\title{
Enfermagem no Ceará: fatos, reflexões e propostas para preservação da história e memória da profissão
}

Nursing in Ceará: facts, reflections and a proposal for the preservation of history and memory of the profession Enfermería en Ceará: factos, reflexiones y propuesta para la preservación de la história y memória de la profesión

\section{Silvia Maria Nóbrega-Therrien', Maria Irismar de Almeida', Marcelo Gurgel Carlos da Silva' \\ 'Universidade Estadual do Ceará, Centro de Ciências em Saúde. Fortaleza, CE}

\section{RESUMO}

O presente estudo demonstra a falta ou insuficiência de registros históricos sobre a Enfermagem no Ceará no intuito de conscientizar os profissionais da área da necessidade de resgatar e preservar a história e memória da categoria. Para promover este objetivo, sugerese criar uma academia de enfermagem no Ceará dedicada à memória, às necessidades atuais e ao desenvolvimento futuro da profissão. Descritores: Enfermagem; História da enfermagem; Sociedades de enfermagem.

\section{ABSTRACT}

The present study demonstrates the lack or insufficiency of historical records regarding the nursing profession in Ceará in the hope of expanding awareness among professionals of the need to rescue and preserve the history and memory of that category. As an additional means to do so, it suggests establishing a nursing academy in Ceará committed to the memory, present needs and future development of the profession.

Descriptors: Nursing; History of nursing; Nursing societies.

\section{RESUMEN}

El presente estudio demuestra la falta o déficit de registros históricos sobre Enfermeria en Ceará com la intención de concienciar a los profesionales del área sobre la necesidad de rescatar y preservar la história y memória de la categoria. Para este objetivo, se sugiere crear una academia de enfermeria en Ceará dedicada a la memória, a las necesidades actuales y al desarrollo futuro de la profesión. Descriptores: Enfermeria; História de la enfermeria; Sociedades de enfermería. 


\section{Introdução}

Este artigo é de natureza reflexiva e é escrito com Quatro intenções Que se complementam. A primeira intenção é evidenciar as dificuldades atuais (2007) de se escrever sobre a História da Enfermagem no Estado do Ceará; a segunda é sensibilizar a consciência histórica da categoria, para o desenvolvimento de iniciativas institucionais, práticas sociais e projetos, Que contemplem o resgate dessa história; a terceira é levar à categoria a reflexões Que permitam observar Que a as informações contidas no passado, contribuem também para o entendimento de Questõescríticas pelas Quais passa a profissão no presente; e a Quarta e última intenção é sugerir à categoria a criação da Academia Cearense de Enfermagem.

\section{CONSTATAÇÕES NECESSÁRIAS PARA AS REFLEXÕES INICIAIS: UMA HISTÓRIA A SER CONTADA}

É uma constatação a falta de um acervo documental de valor histórico sobre a Historia da Enfermagem no Ceará, para consulta de usuários interessados provenientes da comunidade acadêmica ou não. Poucos estudos foram desenvolvidos com esse objetivo de resgate e, consequentemente, de preservação dessa História, entre eles destacam-se os das enfermeiras e professoras Eneida Schramm Frazão e Ivanilda Bruno Osório. Frazão ${ }^{(I)}$ é pioneira neste tipo de investigação no Estado. Lançou em 1973 uma resenha histórica por ocasião dos 30 anos de comemoração da Escola de Enfermagem São Vicente de Paulo. Mais recentemente, em março de 2007, Osório( ${ }^{(2)}$ lançou um livro cujo título é "Memórias de uma enfermeira". Ao relatar sua história de vida, a autora resgata também uma parte da História da Enfermagem no Ceará. As duas publicações utilizaram recursos próprios, o Que evidencia a falta de compromisso institucional.

As constatações dessa evidência (falta de acervo e/ou publicações sobre o tema) se fazem ao longo de muitos anos, principalmente em datas comemorativas da categoria. Na compreensão de

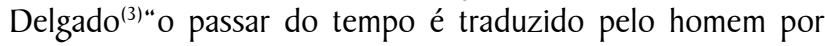
referências celebrativas, comemorativas e identificadoras do cotidiano". Para Bosi( ${ }^{(4)}$, as datas são "pontos de luz", Que permitem vislumbrar na densidade acumulada dos eventos e, no movimento da História, a dinâmica dos tempos.

No caso da Enfermagem no Ceará, a resenha histórica publicada pela enfermeira e professora Frazão foi alusiva às comemorações dos 30 anos da EESVP. Por ocasião da comemoração dos 50 anos do Curso de Enfermagem da Universidade Estadual do Ceará-UECE, em 1993, a falta de acervo foi sentida e alguns discursos foram elaborados com bases em depoimentos e informações coletadas somente para este fim, limitando o seu registro a algumas menções feitas pelos jornais da época.

A falta de acervo também foi sentida por ocasião da comemoração dos 50 anos de ABEN-CE, Que despertou nos membro de sua diretoria à época (2001) a necessidade de registrar a história desta Associação desde sua criação em um documento alusivo ao seu cinqüentenário. Dessa proposta, surgiu um livro como parte dessa comemoração com o titulo "Associação Brasileira de Enfermagem 50 anos: uma viagem através da história”. A proximidade de comemoração dos 30 anos do Curso de Enfermagem da
Universidade Federal do Ceará-UFC, foi outro momento em Que se constatou a falta ou a insuficiência de registro sobre essa história.

Mais recentemente ao se escrever um artigo sobre "Ensino de Enfermagem no Ceará de 1942-1956: a memória Que projeta o futuro" relatou-se Que este marco inicial (1942) correspondia ao início do ensino de Enfermagem no Estado e o terminal (1956), ao acervo disponível Que remetia a Quatro Quadros de madeira de concludentes das primeiras turmas (hoje pertencente ao Curso de Enfermagem da UECE). Para realização do estudo foi necessário descobrir sujeitos significativos Que viveram a época pesquisada. Estas constatações indicam por um lado, a necessidade urgente de resgate e preservação de acervo caseiro, inclusive iconográficos, Que se encontra dispersos. Por outro, remete a necessidade de criação de um espaço Que receba e preserve este patrimônio. Atualmente (março 2007), no Ceará, os estudos de cunho histórico sobre a Enfermagem, se ressentem de acervos seguros para consultas, como ficou demonstrado.

\section{HISTÓRIA E MEMÓRIA: ALGUMAS CONSIDERAÇÕES E INTERSEÇÕES PARA UM TEMPO DE TRANSFORMAÇÕES}

Cabe tecer inicialmente algumas considerações sobre a relação da memória com a História, na perspectiva de sensibilização da consciência histórica de enfermeiras e enfermeiros, e conseqüentemente de estudos e encaminhamentos para sua recuperação e preservação. Não é intenção fazer aQui uma análise sobre estas categorias, (História e memória) uma vez Que não possuímos estudos aprofundados para tal e ainda porQue o tema é denso e complexo e mais ainda pelo que já existe de publicações sobre memória e História, Que as conceituam e as compreendem como categorias distintas, mescladas, mas nunca opostas.

Entre estas publicações se encontram as de Le Goff ${ }^{(5)}$, Que afirma Que a memória e a História se fertilizam mutuamente, chegando mesmo a se confundirem; Delgado 3 Que entende Que memória e História são contraposições ao esQuecimento, são suportes da consciência individual e coletiva Que possibilitam inúmeras leituras do passado; Guarinello ${ }^{(6)}$, Que entende História e memória como processos diferentes, mas não opostos; Nora e outros ${ }^{(7)}$, Que a identificam, a História como produção intelectual do saber e, portanto, como processo cognitivo destruidor da memória espontânea. Estas compreensões poderiam ser finalizadas com considerações de Delgado $^{(3)}$, Que acredita que a História faz da memória uma de suas principais fontes de conhecimento e afirma Que fica claro Que a oposição entre história e memória não chega a ser real.

A memória tem também outras concepções Que não a articulam propriamente a História, mas a remetem (ligam) a tempo, temporalidade, passado, e identidade, desmistificando-a como simples ato de recordar. Chauí ${ }^{8}$ distingue seis tipos de memória: a memória perceptiva ou reconhecimento; a memória hábito; a memória fluxo de duração pessoal, a memória social ou histórica; a memória biológica da espécie e a memória artificial das máeuinas: Meneses ${ }^{(9)}$ estabelece pelo menos cinco de suas dimensões: epistemológica, técnica, existencial, política e a socioeconômica; e Lowenthal ${ }^{(10)}$ Que a identifica como uma de suas três principais fontes de conhecimento sobre o passado, sendo as outras duas, a história e os fragmentos. Este pequeno Quadro de referências denota sua complexidade bem como a 
existência de estudos aprofundados sobre ela.

A História por sua parte também é articulada a tempo e temporalidade, tempo e acontecimentos, tempo e espaço. Como manifestação do fazer coletivo, incorpora vivências individuais, e por decorrência, no mínimo duas dimensões: temporal coletiva e temporal Individual(3). A História é forma intelectual de conhecimento e a memória, ao contrario, é operação ideológica.

Entende-se Que a História e a memória competem à tarefa de empreender o conhecimento do passado, no caso, da Enfermagem e entendemos também Que Questões como estas precisam ser respondidas: Quem são os sujeitos construtores Que tecem a história da enfermagem no Ceará? Quem são as enfermeiras e enfermeiros Que, em sua vida pública, contribuíram para o engrandecimento da profissão nesse Estado? Quem são as enfermeiras e enfermeiros Que merecem ser lembrados porque fizeram de suas convicções, ações? Quem são as enfermeiras e enfermeiros Que anonimamente ou publicamente deixaram sua marca na Enfermagem? Como fazer jus a estas(es) enfermeiras e enfermeiros? Como torná-las(los) reconhecidos como referencia de uma Historia? Como resgatar, preservar e disponibilizar esta História e memória?

\section{ENFERMAGEM: SOBRE A PRESERVAÇÃO DE SUA HISTÓRIA E MEMÓRIA}

Como era comum, àQuela época, ano de 1943, hábeis artesãos eram chamados para esculpir, na madeira, os Quadros Que registravam as turmas de formandos do Curso de Enfermagem da Escola São Vicente de Paulo, Quadros, a época, obras de grande valor, se não do ponto de vista estético, mas pelo forte impacto emocional e histórico, posto Que deixavam gravadas homenagens a pessoas especiais e perpetuavam o registro destas informações, e conseQüentemente o frescor da juventude das enfermeiras recémgraduados. As informações e fotos incrustadas nesses Quadros, ainda existentes e sob a guarda da UECE, permitem construir parte da história desse ensino, Quando complementadas e enriQuecidas pelos depoimentos dos Que viveram à época. Podemos dizer que institucionalmente, esse é o nosso patrimônio histórico.

Pouco resta da História e memória da Enfermagem no Ceará e o Que ainda existe encontra-se disperso. Quase toda a documentação sobre o primeiro curso para enfermeiras, consequentemente documentos referentes à vida da primeira escola criada no Estado, a Escola de Enfermagem São Vicente de Paulo há exatamente sessenta e Quatro anos, não mais existe, pelo menos preservada a nível institucional. A Escola foi fundada em 1943, passou no ano de 1955 a integrar as unidades didáticas da UFC, na condição de Escola agregada e, posteriormente, em 1975, a Escola é encampada pela UECE em 14 de março do ano citado.

Atribuímos à perda desta memória a três fatores Que não são excludentes: primeiro, as mudanças ocorridas nesse período Que envolve o transporte e acondicionamento do acervo e, portanto, da história da Escola para outros campi; segundo, o acondicionamento inadequado por parte da instituição recebedora, no caso a UECE, de tão preciosa documentação; e terceiro, a falta de consciência histórica das enfermeiras na época, sobre a importância deste acervo para profissão.

Hoje, junho de 2007, a existência dos Quatros Quadros talhados em madeira Que perpetuam as turmas de concludentes do início da Escola permanecem desafiando a umidade do ambiente, onde foram colocados, e seguem duelando no tempo, esperando que a consciência histórica das enfermeiras seja despertada.

O reconhecimento dos lastros do Que passou é um dos principais suportes da consciência histórica e como tal não pode se perder. Na compreensão de Delgado (3): "reconhecer o passado é também, na dinâmica da história, construir conhecimento, defender o presente e resguardá-lo como matéria-prima para o futuro". Recompor o passado em sua integridade não é tarefa impossível. Buscar compreendê-lo através da analise de diferentes tipos de documentação e fontes, é desafio possível de ser enfrentado. Entende-se Que um dos caminhos para enfrentamento desse desafio estaria na criação da Academia Cearense de Enfermagem.

\section{A ACADEMIA CEARENSE DE ENFERMAGEM: UMA PROPOSTA DE COMPROMISSO COM A HISTÓRIA, A MEMÓRIA E O PRESENTE DA PROFISSÃO}

A Academia tem um compromisso com a História, mas o tem também com o presente, Quando luta por um ensino de Qualidade, pela valorização do trabalho e pelo direito à saúde de todos os cidadãos. Para Carvalho ${ }^{(1)}$ a Academia Cearense de Medicina não se limita ao registro das ocorrências históricas da Medicina no Ceará, mas também deseja influir na construção dessa história ${ }^{(11)}$.

As instituições de ensino de graduação mais tradicionais no campo da saúde floresceram no Ceará ainda na primeira metade do século XIX, instaladas nos seguintes anos: Farmácia (1916), Odontologia (1916), Enfermagem (1943) e Medicina (1948); dessas profissões, como se demonstra, a seguir, apenas a Enfermagem não conta com a sua Academia específica.

A Academia Cearense de Medicina foi criada em 12 de maio de 1978. Em 20 de janeiro de 1979, foi criada a Academia Cearense de Farmácia, com a finalidade de sustentar, no tempo, e projetar, no espaço, a Farmácia, no Ceará, e incentivar, por todos os meios ao seu alcance, as atividades culturais, científicas e artísticas de seus membros. A Academia Cearense de Odontologia foi, por sua vez, fundada em 23 de setembro de 1984, tendo por finalidade promover o desenvolvimento cultural e científico da Odontologia, a elaboração de sua história e a preservação de sua memória, no Estado do Ceará.

Pelas descrições acima, nota-se Que QualQuer dessas Academias privilegia, entre as suas atribuições, os aspectos históricos e culturais da prática profissional, exercendo um papel complementar às entidades de classe, como Conselhos, Sindicatos e Associações ou Sociedades Especializadas, somando esforços em prol da valorização de cada uma das categorias.

Levantamento efetuado sobre a existência de Academias de Enfermagem no Brasil se identificou apenas a da Academia Brasileira de Especialistas em Enfermagem (ABESE), uma entidade de classe de caráter científico e cultural, sem finalidades lucrativas, constituída por Sociedades e Associações de Especialistas em Enfermagem, com validade em todo o território nacional. A entidade em tela, fundada em 02/10/2000, com sede e foro na capital paulista, não congrega, todavia, os profissionais de Enfermagem, e sim, os órgãos dessa classe.

Tal como aconteceu com a Academia Cearense de Letras, Que 
Enfermagem no Ceará: fatos, reflexões e propostas para preservação da história e memória da profissão

se antecedeu na criação da sua congênere, a Brasileira de Letras, sugerimos aqui Que os enfermeiros do Ceará estejam na vanguarda nacional, na fundação da primeira Academia de Enfermagem do país, de âmbito estadual, constituindo um exemplo a ser imitado por outras unidades federativas. Está-se evidenciando nestas reflexões a urgência dessa criação como caminho de reconstrução e preservação da sua história. A academia seria também um espaço de luta por um ensino de Qualidade, pela valorização do trabalho e pelo direito à saúde de todos.

\section{CONSIDERAÇÕES FINAIS}

A Questão está aberta e a história não existe se não for registrada, contada e preservada. Do exposto se conclui a necessidade de historicizar a memória e, portanto, multiplicar as contribuições Que se insiram numa linha, no caso, de História da Memória da Enfermagem, fazendo justiça aos precursores desta história e conseQuentemente construindo um porto seguro (um patrimônio) para o presente e o futuro dessa profissão.

\section{REFERÊNCIAS}

1. Frazão ES. 30 anos: Escola de Enfermagem São Vicente de Paulo 1943-1973. Fortaleza (CE); 1973.

2. Osório IB. Memórias de uma enfermeira. Fortaleza (CE): LCR; 2007.

3. Delgado LAN. História oral: memória, tempo e identidade. Belo Horizonte (MG): Autêntica; 2006.

4. Bosi A. O tempo e os tempos. In: Novaes A, organizador. Tempo e história. São Paulo (SP): Companhia das Letras; 1992.

5. Le Goff J. História e memória. Campinas (SP): UNICAMP; 1999.

6. Guarinello NL. Memória coletiva e história científica. Rev Bras História 1994; (28): 190-208.
7. Nora P. Entre a memória e a história: a problemática dos lugares. Projeto História. São Paulo (SP): EDUC; 1993.

8. Chauí M. Convite à filosofia. São Paulo (SP): Ática; 1995.

9. Meneses UTB. A crise da memória, história e documento: reflexões para um tempo de transformações. In: Silva ZL, organizador. Arquivos, patrimônio e memória: trajetórias e perspectivas. São Paulo (SP): EDUNESP/ FAPESP; 1999. p.II-30.

10. Lowenthal D. Como conhecemos o passado. Projeto História. São Paulo (SP): EDUC; 1998.

11. Carvalho VPL. Discurso de posse na Presidência da Academia Cearense de Medicina. Fortaleza (CE); 2003. 